\title{
Linear Viscous Approach to Predict Rut Depth in Asphalt Mixtures
}

\author{
Hasan Al-Mosawe ${ }^{1, *}$, Nick Thom ${ }^{2}$, Gordon Airey ${ }^{3}$, Amjad Albayati $^{\mathrm{b}}$ \\ ${ }^{a}$ Civil Engineering Department, The University of Nottingham, UK \\ ${ }^{b}$ Civil Engineering Department, The University of Baghdad, Iraq
}

\begin{abstract}
Rutting in asphalt mixtures is a very common type of distress. It occurs due to the heavy load applied and slow movement of traffic. Rutting needs to be predicted to avoid major deformation to the pavement. A simple linear viscous method is used in this paper to predict the rutting in asphalt mixtures by using a multi-layer linear computer programme (BISAR). The material properties were derived from the Repeated Load Axial Test (RLAT) and represented by a strain-dependent axial viscosity. The axial viscosity was used in an incremental multi-layer linear viscous analysis to calculate the deformation rate during each increment, and therefore the overall development of rutting. The method has been applied for six mixtures and at different temperatures. Finally, field data has also been used to check the applicability of the approach in real pavement design.
\end{abstract}

Keywords:

asphalt mixtures, multi-layer linear viscous analysis, rutting, prediction,

BISAR

\footnotetext{
* Corresponding author

Email addresses: evxhmal@nottingham.ac.uk, almosawe88@gmail.com (Hasan Al-Mosawe), nicholas.thom@nottingham.ac.uk (Nick Thom),

gordon.airey@nottingham.ac.uk (Gordon Airey), sirtransportation@yahoo.com (Amjad Albayati)

${ }^{1} \mathrm{Ph} . \mathrm{D}$. Student

${ }^{2}$ Assistant Professor

${ }^{3}$ Professor

${ }^{4}$ Assistant Professor
}

Preprint submitted to Construction and Building Materials 


\section{Introduction}

The main form of permanent deformation in asphalt mixtures is rutting. Many studies have investigated the mechanism of rutting formation and how to optimise material proportions to avoid it. Permanent deformation is a key issue in asphalt pavement design especially in places with high temperatures, and it can be determined by using triaxial testing $[1,2,3]$. Rutting needs to be predicted to avoid major deformation to the pavement.

Generally, it is well known that the response of an asphaltic mixture depends on loading time and temperature. Asphalt concrete mixtures behave as linear visco-elastic materials under low temperature conditions (or short loading times), while they behave as non-linear elasto-viscoplastic materials under high temperature conditions (or long loading times). When asphaltic mixtures behave as linear visco-elastic materials, they can be modelled using one of the physical models in which the model components are arranged as springs and dashpots either in parallel or in series to best fit test results.

There are two main approaches for predicting asphalt mixture rutting: the layer-strain method and the visco-elastic approach. The layer-strain method can predict the life until rutting failure in asphalt mixtures by assuming a linear or non-linear relationship between the elastic stress field and vertical permanent deformation in each selected layer. This approach is only dependent on the elastic properties of the mixture and does not directly use the material viscosity [4]. Prediction models based on the visco-elastic approach invariably include a timedependant response to the wheel load [4]. This type of rutting prediction model assumes that the ruts accumulate mainly from the shear flow of the pavement material. The visco-elastic approach is, unlike the layer-strain approach, purely dependent on the viscous characteristics of the asphalt and independent of the elastic properties. The visco-elastic properties of asphalt mixtures are, typically, measured from confined or unconfined creep testing. The method of linear viscoelastic asphalt material simulation and rutting prediction of asphalt concrete mixtures has been investigated by several researchers, $[5,6,7,8,9,10,11]$. 
The asphalt mixtures are assumed to behave as linear visco-elastic materials in this type of model, and this is considered as the main drawback of the approach. In reality, asphalt mixtures behave non-linearly at high temperatures and stress levels. However, the implementation of the non-linear properties of asphalt mixtures in modelling demands a more advanced tool.

The aim of this paper is to develop a practical and usable method by modifying a simple linear viscous multi-layer model, to enable the prediction of wheel track rut depth. The modified approach incorporates the non-linear properties of the asphalt mixture into the analysis.

\section{Linear Viscous Approach}

Permanent deformation in asphalt mixtures is due to the movement between adjacent particles, surrounded by a thin layer of bitumen. The rheological properties of this binder film govern the deformation in the mixture [12]. The principle of linear viscous analysis is analagous to linear elastic, except that the elastic parameter (Young's modulus) is replaced by the equivalent viscous parameter (viscosity) [11]. [9] presented a viscous method to predict the permanent deformation in an asphalt mixture. The method was based on the use of the viscous part of the material behaviour; steps to predict the rut depth were as follows:

1. A plot of mixture stiffness $\left(S_{m}(t)\right)$ against loading time was derived from creep testing.

2. The binder properties (softening point and penetration) were used to produce binder stiffness $\left(S_{b}(t)\right)$ against loading time.

3. The two curves were then combined to generate a plot of $S_{m}(t)$ versus $S_{b}(t)$.

4. An equivalent loading time for a given number of commercial vehicle passes was then calculated at an effective temperature and used to derive the $S_{m}(t)$, and then the axial viscosity.

5. The axial viscosity was then utilised in a multi-layer linear viscous analysis to calculate the permanent deformation accumulated in each increment of 
the number of commercial vehicles passes (new loading time).

The equation to determine the axial viscosity of the mixture $(\lambda)$ was as follows:

$$
\lambda_{m}(t)=\frac{\sigma}{\dot{\varepsilon}}=\frac{1}{\frac{d}{d t}\left(\frac{1}{S_{m}(t)}\right)}
$$

He used the axial viscosity with the deformational Poisson's ratio in a multilayer linear viscous analysis to determine the average rate of permanent strain and the accumulated permanent deformation in the whole pavement layer. A uniaxial creep test was conducted at $30{ }^{\circ} \mathrm{C}$ to measure the deformation of the mixture and a constant stress of $100 \mathrm{kPa}$ was used. The predicted results showed an accuracy of $\pm 30 \%$ compared to the measured deformation.

\section{Material and Testing Programme}

\subsection{Material}

Six different aggregate gradations have been selected, to cover a range of possible variations, within the limits of $14 \mathrm{~mm}$ maximum aggregate size Asphalt Concrete according to $B S E N$ 4987-1:2005. The aggregate used was granite; the aggregate blend for each gradation was mixed with a $5.1 \%$ binder content of $40 / 60$ penetration grade at $160{ }^{\circ} \mathrm{C}$. The aggregate gradation details are shown in Figure 1. The aggregate and binder were heated up to $160 \pm 5{ }^{\circ} \mathrm{C}$ for a minimum period of 8 hours; at the same time, the binder was also heated up to $160 \pm 5{ }^{\circ} \mathrm{C}$ but for $3-5$ hours only. The aggregate blends and binder were then mixed in a mechanical mixer at $160 \pm 5{ }^{\circ} \mathrm{C}$ for approximately 3 minutes. After that the mixture was compacted by roller compactor at $150 \pm 5{ }^{\circ} \mathrm{C}$ with target air voids of $5 \%$ to make a slab of $306 \times 306 \times 50 \mathrm{~mm}$. The slabs were then tested in a wheel tracker machine and cores subsequently taken from areas outside the wheel path.

Each slab was tested in the wheel tracker according to BS EN 12697-22:2003. The temperature used was $40{ }^{\circ} \mathrm{C}$ and the load applied was $670 \mathrm{~N}$; the test duration was 20000 passes (10000 cycles). 


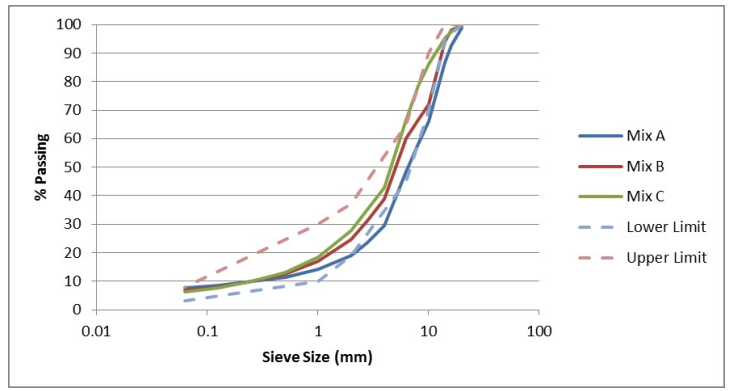

(a) Mix A, B, and C

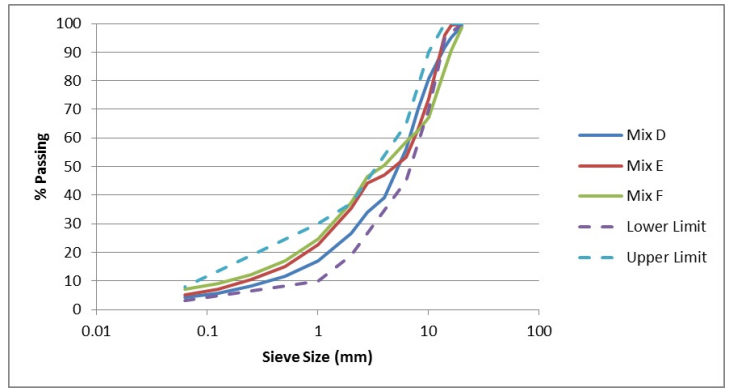

(b) Mix D, E, and F

Figure 1: Aggregate Gradations for Asphalt Mixtures

\subsubsection{Repeated Load Axial Test (RLAT)}

The RLAT (or dynamic creep) test simply consists of a vertical stress repeatedly applied to the cores that were taken from the region outside the rut line in the slab. The core dimensions were $100 \mathrm{~mm}$ diameter by $50 \mathrm{~mm}$ height. The test applies a stress for 1 second to the sample followed by a 1 second rest period. In this study, the cores from each slab were tested under a stress level of $300 \mathrm{kPa}$ and at $40{ }^{\circ} \mathrm{C}$ for 5000 cycles (10000 seconds). The test procedure was performed according to British Standards DD 226:1996.

\section{Methodology}

The method used to predict asphalt concrete wheel track rut depth in this paper is based on using the strain-dependent properties of the asphalt mixture in a multi-layer linear viscous analysis. The methodology can be summarised 
as follows:

1. Produce the laboratory rut depth curve by testing the slab samples in the wheel tracking machine.

2. Four cores are then taken from the tested slab (from regions outside the rut line) and tested in the RLAT under a value of stress (300 kPa) close to that applied during wheel tracking.

3. Calculate the strain rate $(\dot{\varepsilon})$ for each RLAT cycle by using the following equation:

$$
\dot{\varepsilon}=\frac{\varepsilon_{2}-\varepsilon_{1}}{t_{2}-t_{1}}
$$

where $t_{2}$ and $t_{1}$ are the time (in seconds = number of cycles) corresponding to strains $\left(\varepsilon_{2}-\varepsilon_{1}\right)$

4. Determine the viscosity $(\eta)$ of the mixture, as a function of strain. Viscosity is computed by dividing the stress $(\sigma)$ in $\mathrm{MPa}$ by the strain rate $(\dot{\varepsilon})[9]$

$$
\eta=\frac{\sigma}{\dot{\varepsilon}}
$$

A plot of mixture viscosity vs strain is then produced and used to establish the viscous material properties for rutting prediction. A typical plot representing a mixture showing all three stages of creep (primary, secondary, and tertiary) is shown in Figure 2.

5. After that, an initial material viscosity is determined from the viscositystrain curve by extrapolating to zero strain. This initial value is then used in the first deformation analysis increment.

6. The asphalt slab is then modelled in BISAR (multi-layer linear analysis) as three layers with thicknesses of 10, 20 and $20 \mathrm{~mm}$, in order to model the wheel tracking test, see Figure 3.

The load input data to BISAR is as follows:

- Vertical stress $(\mathrm{kPa}): 300$. This value corresponds to the stress in the wheel tracking test.

- Radius (m): 0.0250. This is the tire width in the wheel tracking test. 


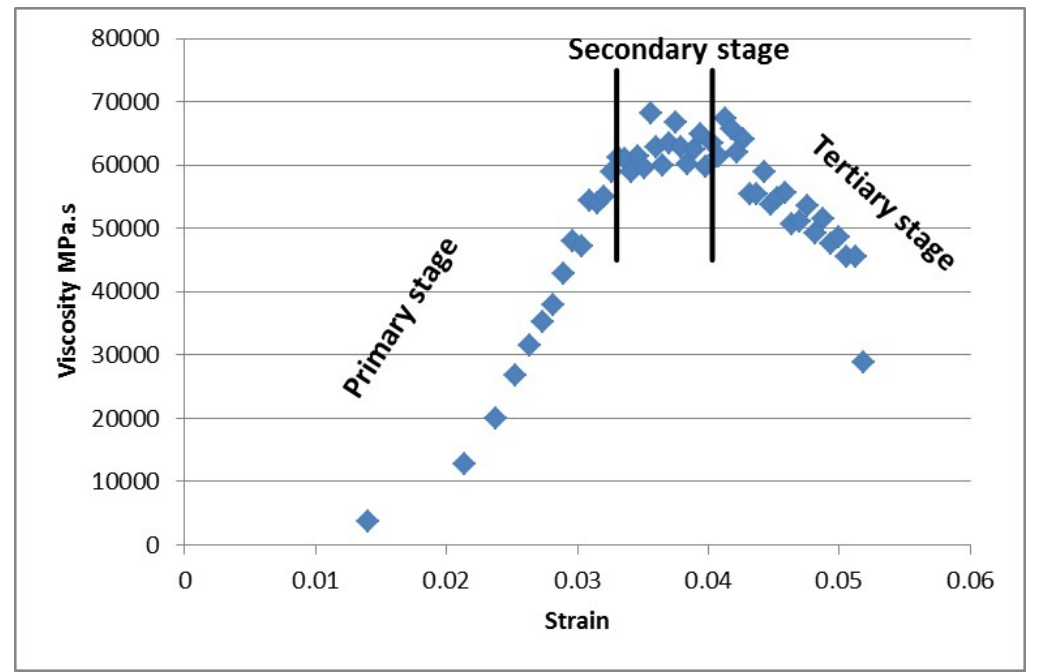

Figure 2: Typical Plot of Viscosity vs Strain for an asphalt mixture

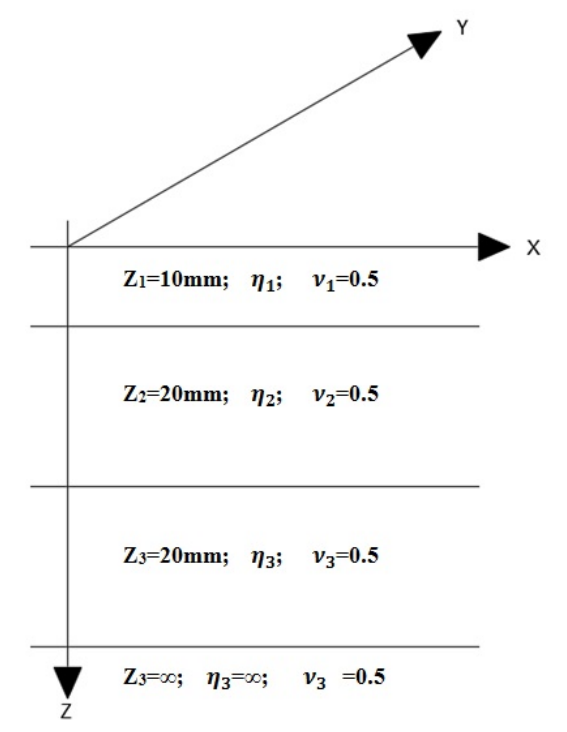

Figure 3: Slab Model Layers divided in BISAR

7. The three layers of asphalt are assigned viscosity values. A final very stiff bottom layer is added (effectively $\infty$ viscosity). All the four layers are assumed to be incompressible (Poissons ratio of 0.5 ) to ensure that 
the deformation is due to viscous flow not densification, and full friction between layers is adopted.

8. The analysis is then performed and the strain rate (strain/second $=$ strain/cycle) in the middle of each layer under the centre of the load is used in further calculations.

9. A surface deformation increment of $0.1 \mathrm{~mm}$ is applied and the layer strains and the number of cycles to cause this increment are determined.

10. The new layer strains require new corresponding viscosities from the strain viscosity curve (Figure 2) established earlier in the process giving new viscosities for each layer; these are used in BISAR for the following deformation increment.

11. Continue this loop until a specified deformation is reached.

No adjustment was made to the loading time because it was similar in both cases (RLAT and wheel track). In the RLAT the stress was applied for 1 second and in the wheel tracking test the rate of loading was 26.5 cycles/minute and each cycle consisted of two passes.

\section{Analysis of Results}

Six slabs were manufactured for six different gradations. The slabs were all tested in the wheel tracking test, and four cores were taken from each slab. This section presents (in Figures 4 - 9) the results of the prediction process and compares these prediction results to the wheel tracking rut depth. The viscosity-strain curves are also be shown for each mix, and a trend line is fitted to the primary stage of each. The best option found was an exponential curve, and it has been used to estimate the values of viscosity where strain is lower than the first point on the curve. After the first data point, linear interpolation was assumed between each two points.

The prediction based on RLAT data for Mix B and C showed, in Figures 5 and 6 respectively, an underestimation compared to the real wheel track curve by about $0.4 \mathrm{~mm}$. 


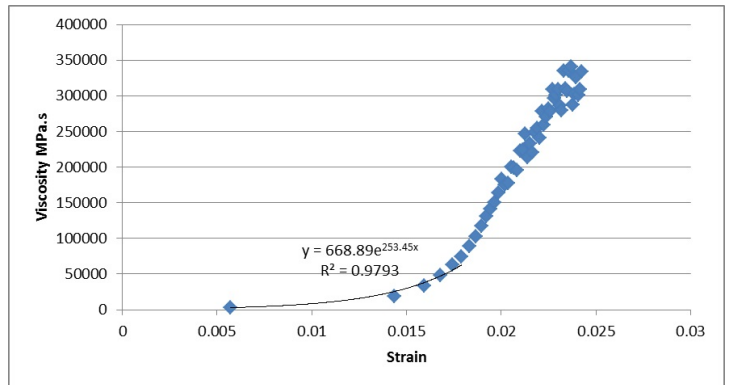

(a)

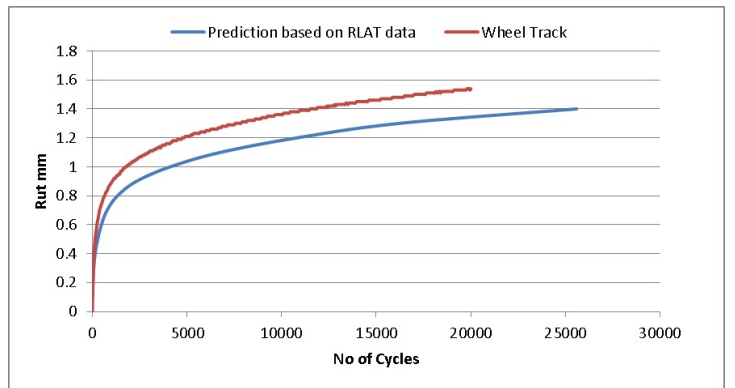

(b)

Figure 4: (a) Viscosity-Strain Curve. (b) Rut Depth Prediction. For Mix A

All these results were based on the properties of material determined at 40 ${ }^{\circ} \mathrm{C}$ in RLAT tests modelling the same conditions as in the wheel track test. Although the stress distribution in the wheel track test is complex and the assumption in BISAR that the model has an infinite width is incorrect, nevertheless the RLAT test provides a reliable and convenient approach to characterising the properties of the asphaltic materials. The reasonable agreement between the predicted and measured deformations confirms the argument that the permanent deformation can be predicted from the viscous properties of the material.

\subsection{Temperature}

As the linear viscous analysis showed good agreement with the experimental data at $40{ }^{\circ} \mathrm{C}$, it was decided to investigate the validity of the method at other temperatures. Two temperatures were selected, $30{ }^{\circ} \mathrm{C}$ and $50{ }^{\circ} \mathrm{C}$. The 


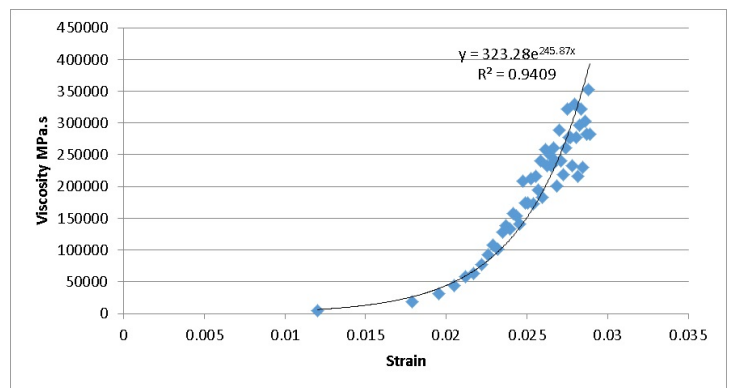

(a)

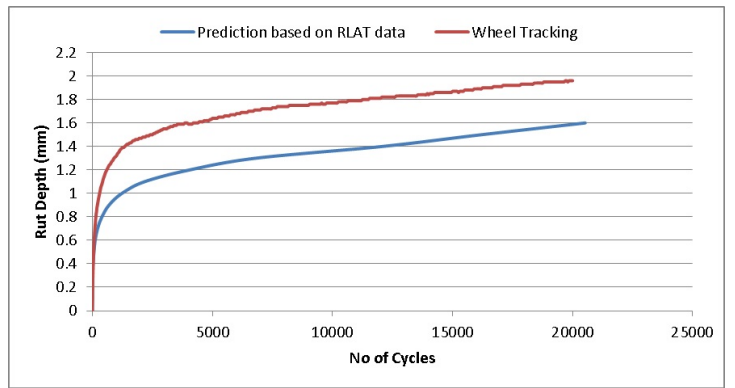

(b)

Figure 5: (a) Viscosity-Strain Curve. (b) Rut Depth Prediction. For Mix B

whole process and experimental work were performed again at $30^{\circ} \mathrm{C}$ for all six mixtures and repeated at $50{ }^{\circ} \mathrm{C}$ for one of the mixtures only because the others were expected to fail in the RLAT test at $50{ }^{\circ} \mathrm{C}$ under $300 \mathrm{kPa}$ stress.

\subsubsection{Prediction at $30^{\circ} \mathrm{C}$}

Six asphalt mixture slabs were manufactured and tested in the wheel tracking machine at $30{ }^{\circ} \mathrm{C}$ under the same load of $690 \mathrm{~N}$, and a frequency of $26.5 \pm 1.0$ load cycles/minute. The slabs were then cored in the region outside the rut line, and cores were tested in the RLAT at $30{ }^{\circ} \mathrm{C}$. The results of predictions at $30{ }^{\circ} \mathrm{C}$ are shown in Figures $10-15$, and it can be seen from the figures that, as expected, the values of viscosity are higher than those determined at $40{ }^{\circ} \mathrm{C}$, and also there is less data scatter than found previously. These two points helped to generate a good set of predictions of wheel tracking rut depth at $30{ }^{\circ} \mathrm{C}$. Mix $\mathrm{A}, \mathrm{B}$, and $\mathrm{D}$ are the most affected by the change in viscosity values compared 


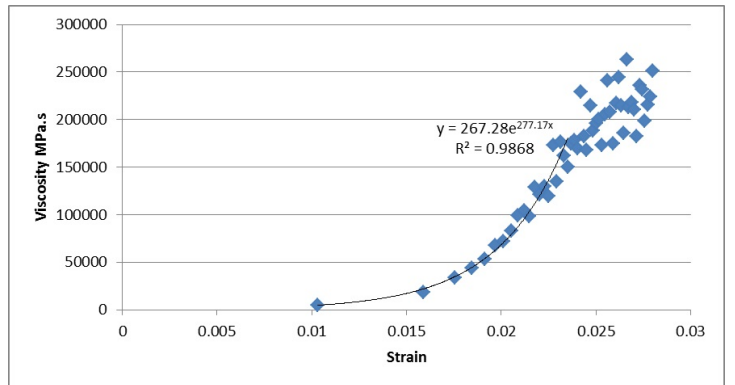

(a)

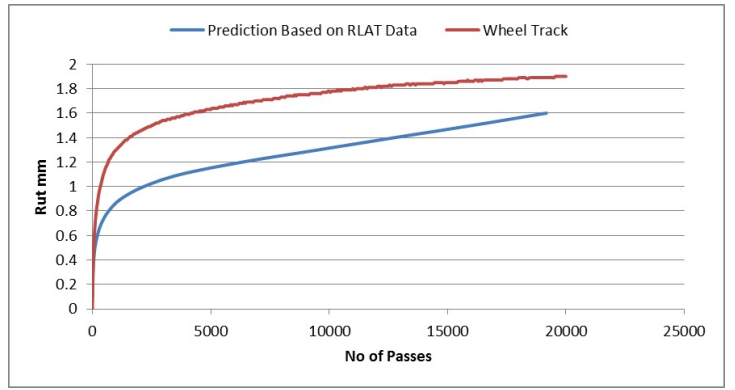

(b)

Figure 6: (a) Viscosity-Strain Curve. (b) Rut Depth Prediction. For Mix C

to results at $40{ }^{\circ} \mathrm{C}$, and it can be seen from the results that their predictions were all reasonably good.

\subsubsection{Prediction at $50^{\circ} \mathrm{C}$}

The higher testing temperature was also examined aiming to validate the methodology. The samples were expected to approach collapse under the 300 $\mathrm{kPa}$ dynamic stress in the RLAT at $50{ }^{\circ} \mathrm{C}$. Therefore, only one of the mixtures was selected. The selected Mixture was Mix F because it is expected to have good aggregate interlock and resistance to permanent deformation. Consequently, one slab was manufactured and tested in the wheel tracking machine at $50{ }^{\circ} \mathrm{C}$ and cores were taken from the outer region and tested in the RLAT at the same temperature $\left(50{ }^{\circ} \mathrm{C}\right)$. As expected, the mixture had high strain values in the RLAT, resulting in small values of viscosity. Figure 16 shows the viscositystrain curve having a decrease in viscosity values at high strains, signifying the 


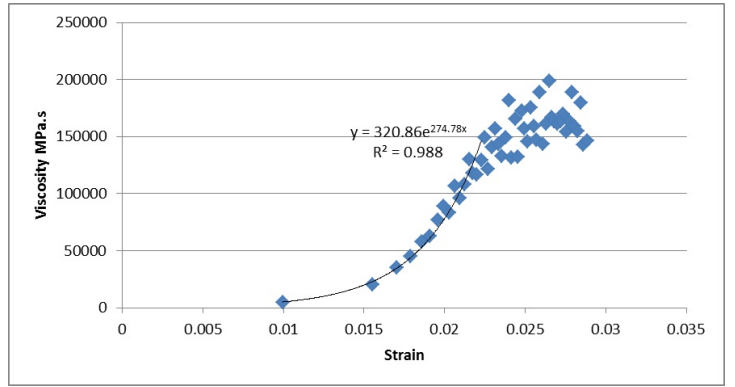

(a)

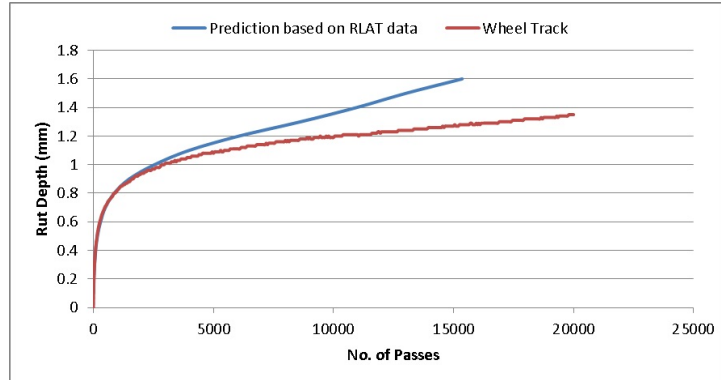

(b)

Figure 7: (a) Viscosity-Strain Curve. (b) Rut Depth Prediction. For Mix D

high accumulation of permanent strain in the tertiary stage of dynamic creep, and it is clear that this has resulted in an unrealistically high rut prediction. 


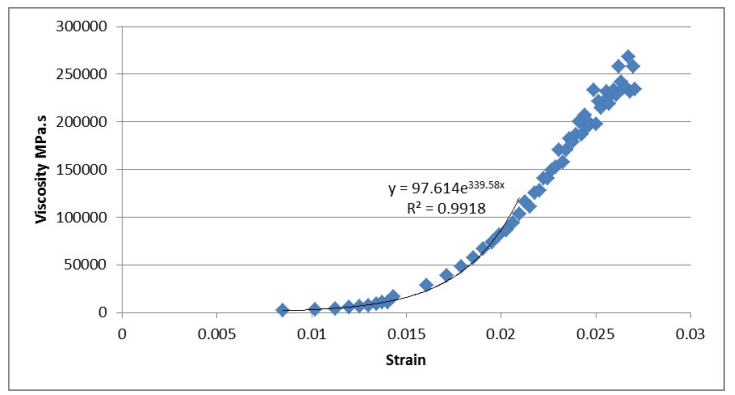

(a)

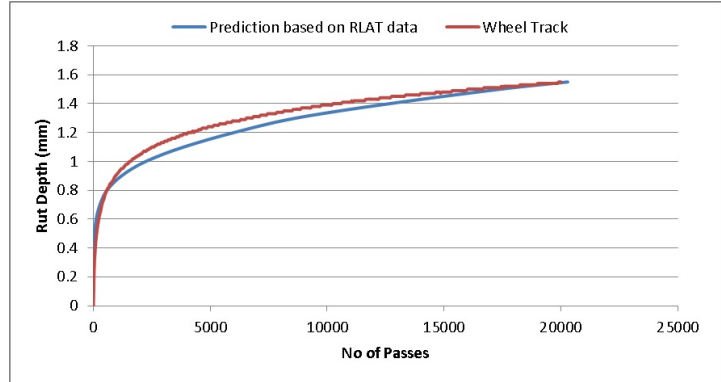

(b)

Figure 8: (a) Viscosity-Strain Curve. (b) Rut Depth Prediction. For Mix E 


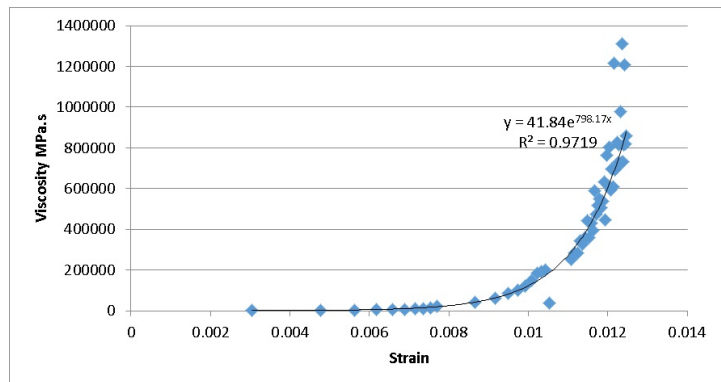

(a)

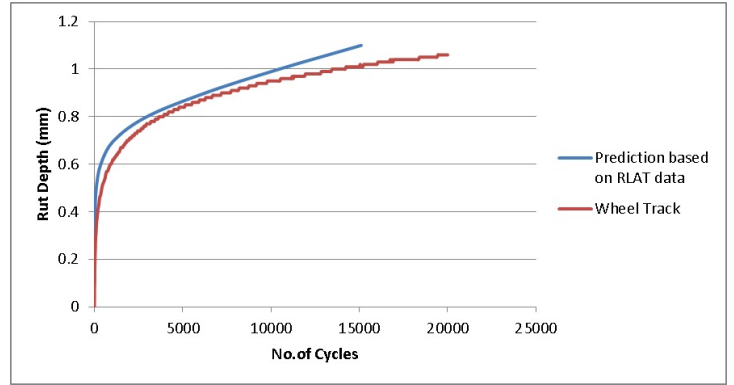

(b)

Figure 9: (a) Viscosity-Strain Curve. (b) Rut Depth Prediction. For Mix F 


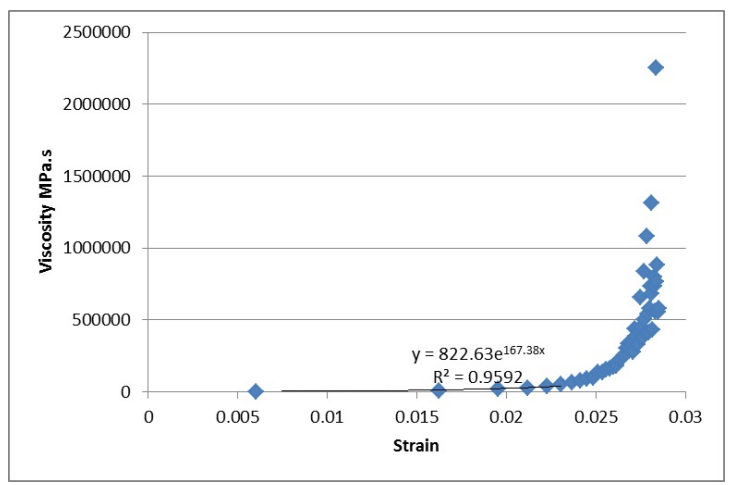

(a)

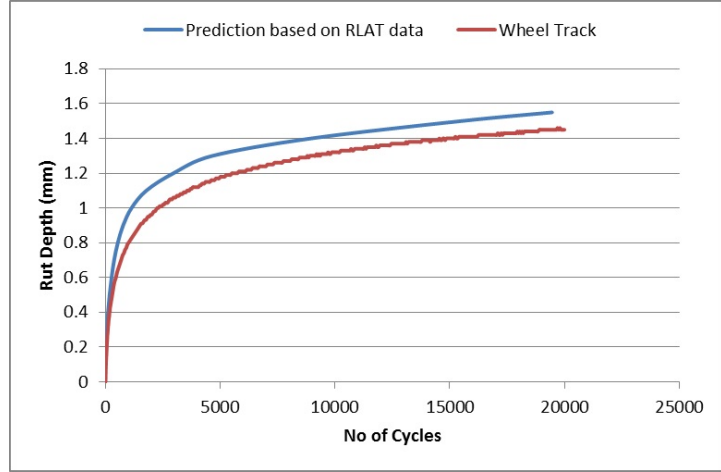

(b)

Figure 10: (a) Viscosity-Strain Curve. (b) Rut Depth Prediction. For Mix A at $30{ }^{\circ} \mathrm{C}$ 


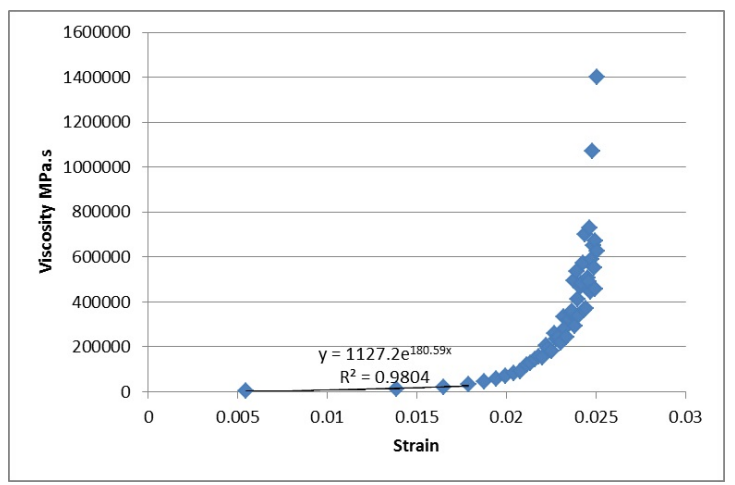

(a)

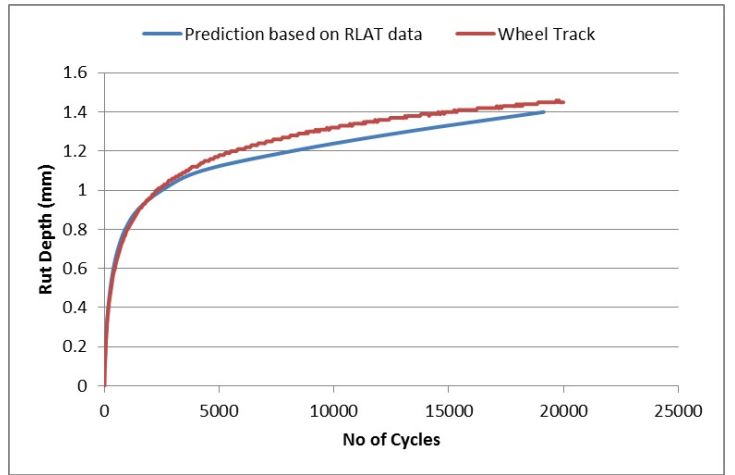

(b)

Figure 11: (a) Viscosity-Strain Curve. (b) Rut Depth Prediction. For Mix B at $30^{\circ} \mathrm{C}$ 


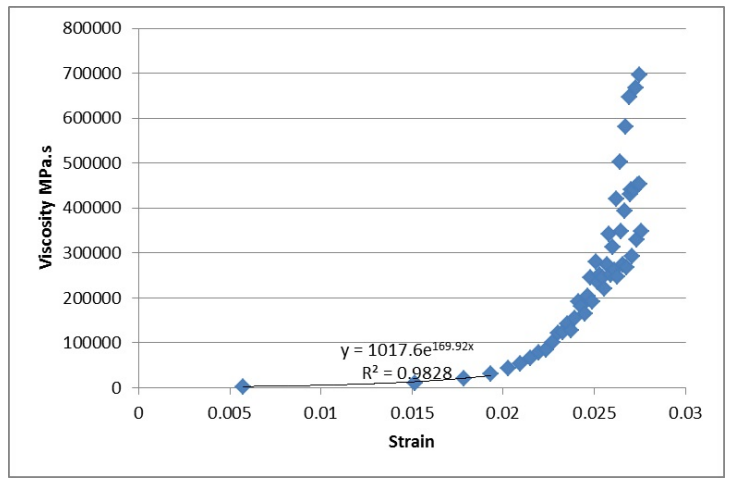

(a)

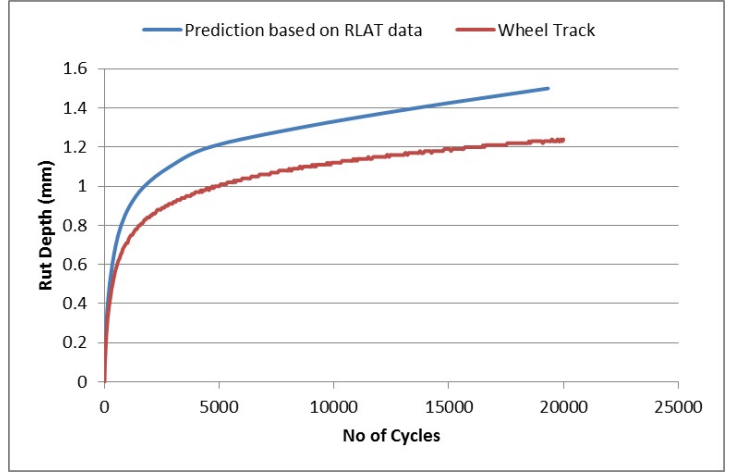

(b)

Figure 12: (a) Viscosity-Strain Curve. (b) Rut Depth Prediction. For Mix C at $30^{\circ} \mathrm{C}$ 


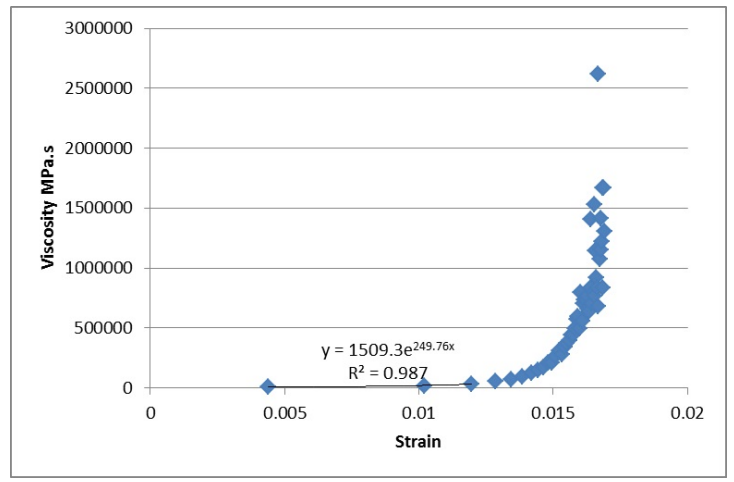

(a)

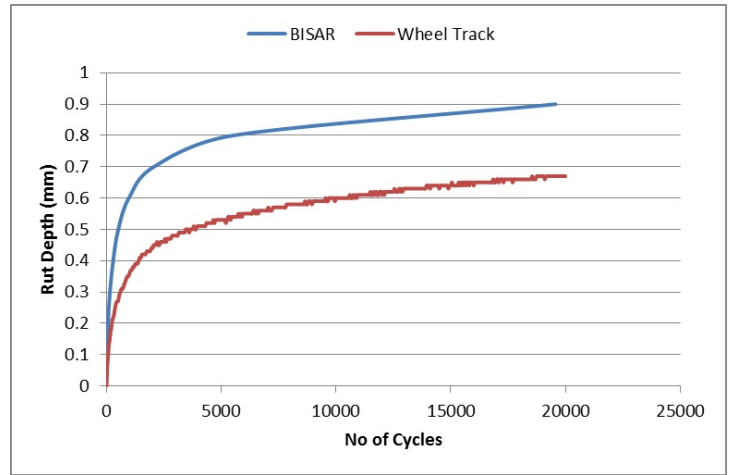

(b)

Figure 13: (a) Viscosity-Strain Curve. (b) Rut Depth Prediction. For Mix D at $30{ }^{\circ} \mathrm{C}$ 


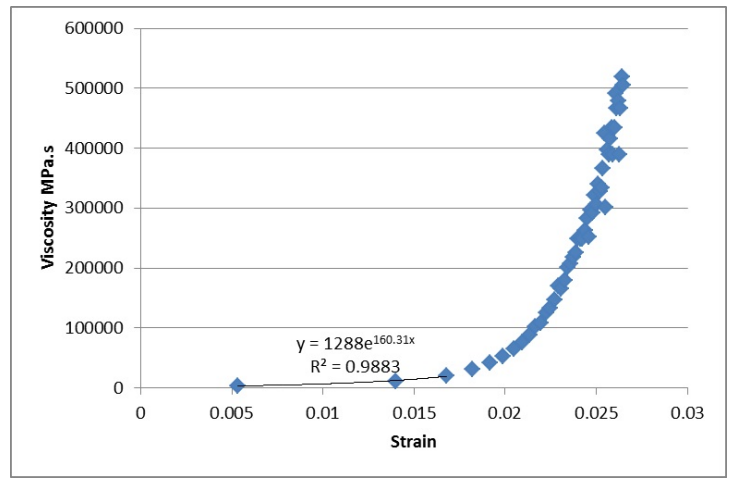

(a)

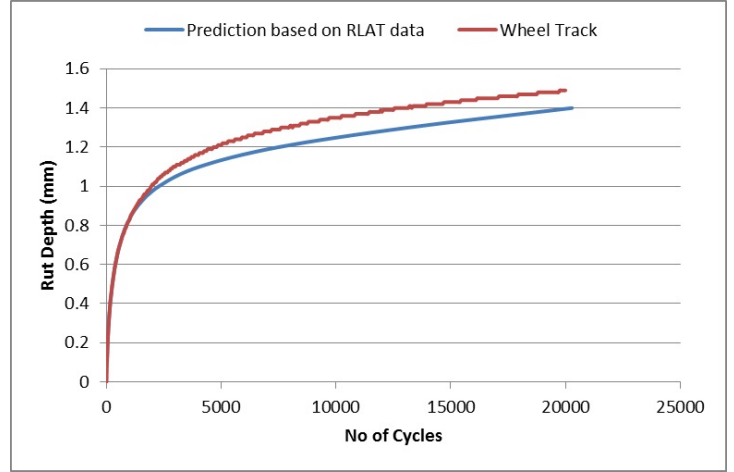

(b)

Figure 14: (a) Viscosity-Strain Curve. (b) Rut Depth Prediction. For Mix E at $30{ }^{\circ} \mathrm{C}$ 


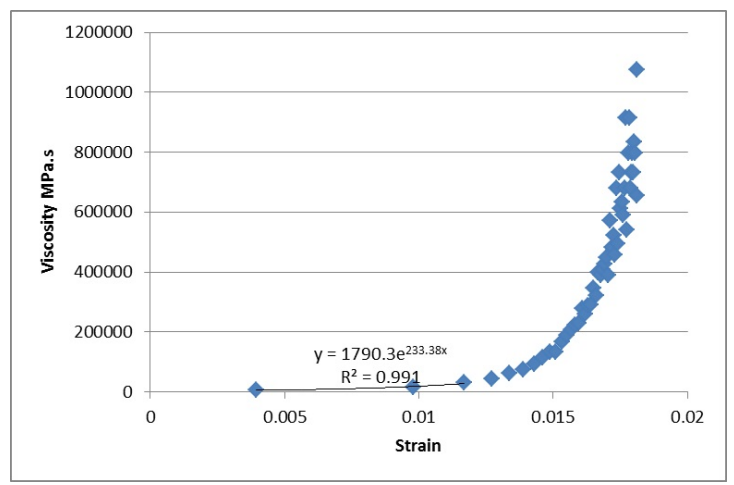

(a)

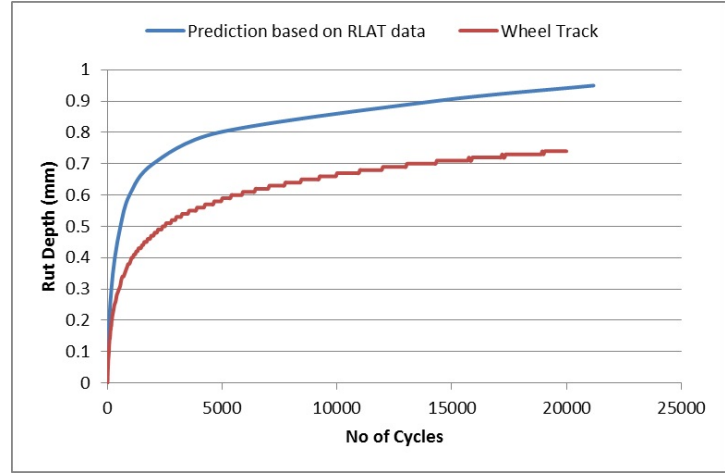

(b)

Figure 15: (a) Viscosity-Strain Curve. (b) Rut Depth Prediction. For Mix F at $30{ }^{\circ} \mathrm{C}$ 


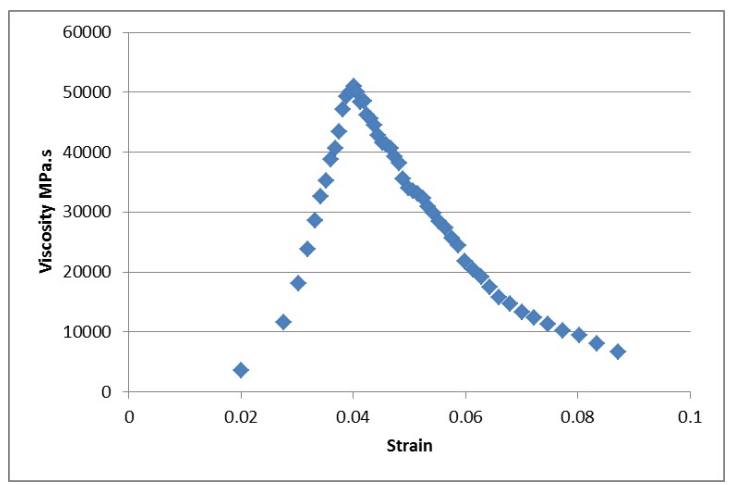

(a)

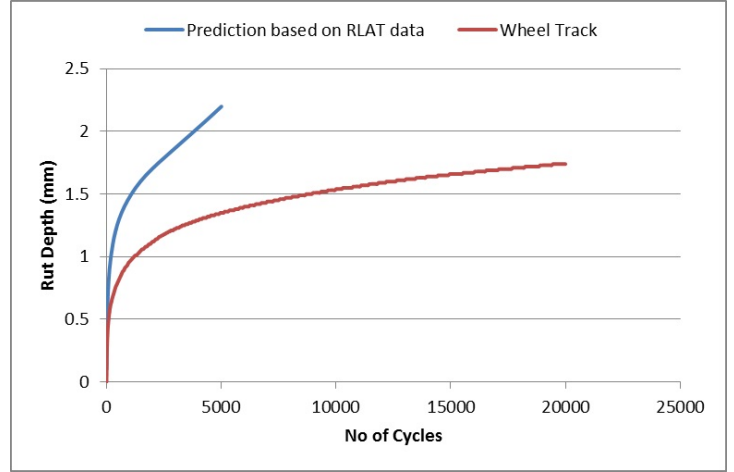

(b)

Figure 16: (a) Viscosity-Strain Curve. (b) Rut Depth Prediction. For Mix F at $50{ }^{\circ} \mathrm{C}$ 


\section{Field Rut Depth Prediction}

\subsection{Data Collection}

The above analysis has also been applied to real road rut depths to check its validity further. Field data were obtained related to a particular rutted road in the UK. The asphaltic layer consisted of three sublayers: $40 \mathrm{~mm}$ thickness of 0/10 mm Stone Mastic Asphalt (SMA) surface course, $50 \mathrm{~mm}$ thickness of 0/20 mm Dense Bitumen Macadam (DBM) binder course, and $135 \mathrm{~mm}$ thickness of 0/32 mm Hot Rolled Asphalt (HRA) base layer. It was noted that rutting to depth of 10-60 mm had taken place within two years of constructing the pavement, so a site investigation was performed, and cores were taken from outside the rutting area, and the cores showed the above thicknesses of each sublayer. The cores were then tested in the RLAT to measure the permanent deformation in each layer and the results were made available to this research. They were tested at $40{ }^{\circ} \mathrm{C}$ under a stress of $100 \mathrm{kPa}$ for 3600 cycles according to $B S D D 226$.

\subsection{Use of Field Data}

The field data report shows an assessment of the three layers to predict which layer is more susceptible to rutting by using an analytical tool called Permanent Deformation Program (PDP). PDP is based on the approach described in Section 2 and it incorporates the RLAT data, initial penetration grade and softening point of binder used in each asphalt layer, and the traffic loading.

The RLAT data from two core locations were utilized for the three sublayers. Viscosity-strain curves were produced for all the asphalt layers, although none reached a viscosity peak. This is because of the relatively low stress applied $(100 \mathrm{kPa})$ and the lower number of cycles compared to the data in the previous section. An exponential function was fitted to the viscosity-strain curves to allow an initial viscosity to be estimated, as shown in Figure 18. The pavement was then modelled in BISAR in three layers with the real thicknesses and a standard wheel load of $40 \mathrm{kN}$ on a radius of $150 \mathrm{~mm}$. The same process as 
presented in section 4 was applied but with extrapolation using the exponential function and $1 \mathrm{~mm}$ deformation increments.

Two issues were considered in performing the analysis: the loading time (speed of the vehicle), and temperature. For the loading time, a previously developed model by [13] was used to relate the loading time to vehicle speed and rut depth:

$$
\log (t)=0.5 d-0.2-0.94 \log (v)
$$

where: $\mathrm{t}=$ loading time $(\mathrm{sec}) ; \mathrm{d}=$ pavement depth $(\mathrm{m})$; and $\mathrm{v}=$ vehicle speed $(\mathrm{km} / \mathrm{h})$. The RLAT loading time of 1 second was used in the above equation with the real depth to obtain an equivalent vehicle speed of $0.81 \mathrm{~km} / \mathrm{hr}$ in the BISAR prediction. The prediction results were compared with a PDP prediction at $1 \mathrm{~km} / \mathrm{hr}$. Concerning temperature, an approximate estimate was made to convert the results from 40 to $26{ }^{\circ} \mathrm{C}$ (stated as the effective field temperature). The temperature shift factor evaluation was based on previous RLAT data at 30,40 , and $50{ }^{\circ} \mathrm{C}$; the initial parts of the 30 and $50{ }^{\circ} \mathrm{C}$ RLAT curves were shifted with respect to $40{ }^{\circ} \mathrm{C}$ by factors of 1.6 and 0.7 respectively, as shown in Figure 17. Extrapolation was made to $26{ }^{\circ} \mathrm{C}$ based on these factors assuming linear behaviour. The extrapolated shift factor for results from $26{ }^{\circ} \mathrm{C}$ to $40{ }^{\circ} \mathrm{C}$ was found to be 1.84. Therefore, all the predicted rut depths in BISAR were multiplied by a factor of $0.54\left(\frac{1}{1.84}\right)$ to convert the predicted data from 40 to 26 ${ }^{\circ} \mathrm{C}$.

\subsection{Prediction Results and Discussion}

The prediction process was performed for 2 locations in the field, taken from region outside rut line. The prediction of the rut is shown in Figure 19 and compared with the PDP prediction after considering the temperature shift factor. By way of comparison the field rut depth was measured to be 10-60 $\mathrm{mm}$ after two years of construction. The form of loading is entirely different in the BISAR and PDP analyses compared to a real load application. The actual wheel load includes the rotational principle stress effects while BISAR and PDP do not. This has a very definite effect on unbound material and may 


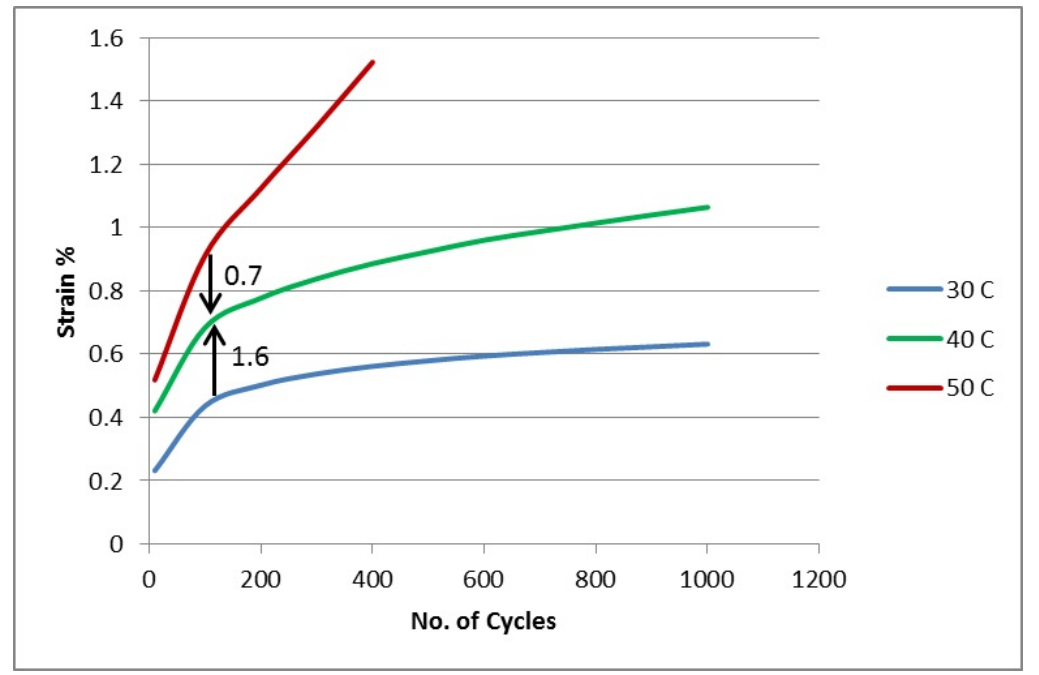

Figure 17: Shifting RLAT data to $40{ }^{\circ} \mathrm{C}$

also have an impact on asphalt mixtures, however it did not show effects on the prediction of wheel track prediction results presented earlier. The BISAR prediction matched PDP regarding the shape of the rut curve (the two stages primary and secondary); however, the process clearly underestimated the total rut depth.

The reason for this underestimation is that the viscosity-strain curve never reached a peak; and the fitted exponential function assumes that the viscosity keeps increasing. This produced very stiff layers of asphalt which then require a high number of Standard Axle (SA) to develop a $1 \mathrm{~mm}$ deformation. This is clearly shown in Figure 19 where the BISAR curves end in a very flat trend.

To overcome this problem, it was planned to fit a Gaussian function to the RLAT data to generate the peak of the viscosity-strain curve. Matlab 2015 was used to fit the RLAT data to the Gaussian function, but unfortunately, it has been found that the function could not be fitted to the data with any confidence. The reason is that the RLAT test was performed under a stress of $100 \mathrm{kPa}$ and a duration of 3600 load applications; these parameters do not allow the sample to reach the tertiary stage; therefore, the function was not able to identify the 


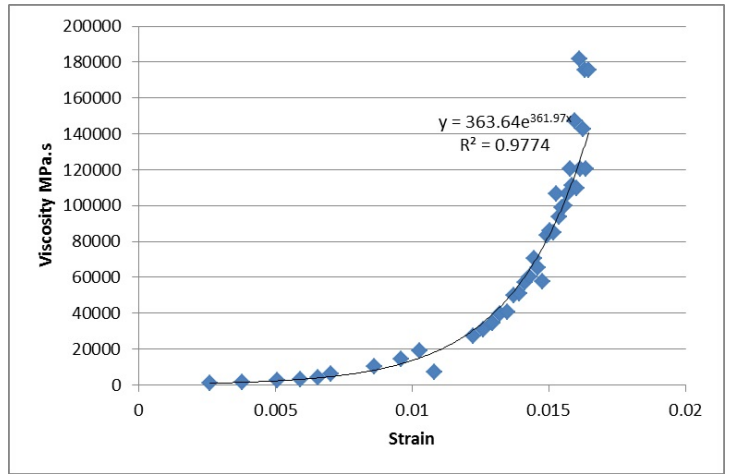

(a)

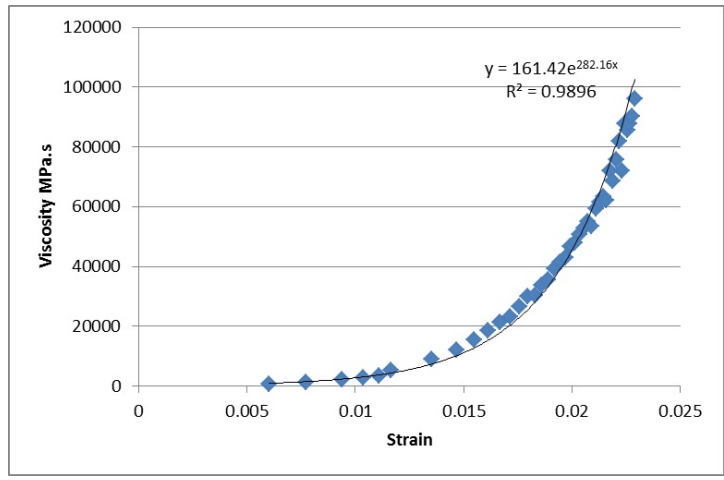

(b)

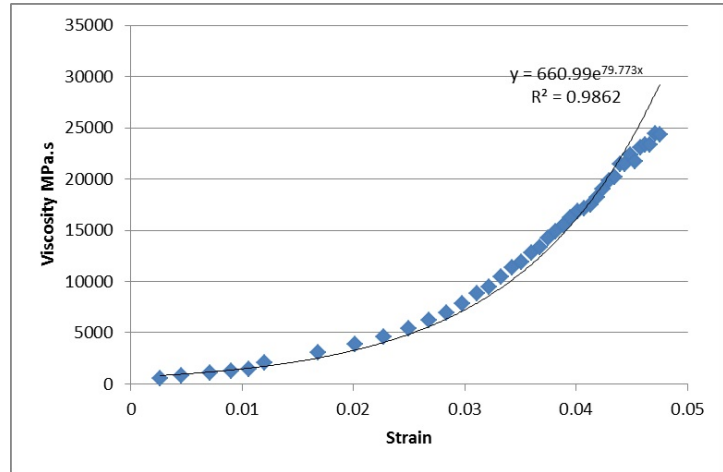

(c)

Figure 18: Viscosity-Strain curve of Core 4 in Field

peak. A trial was performed to estimate the strain value which corresponded to the peak viscosity for each layer but it was found that it was difficult to estimate 


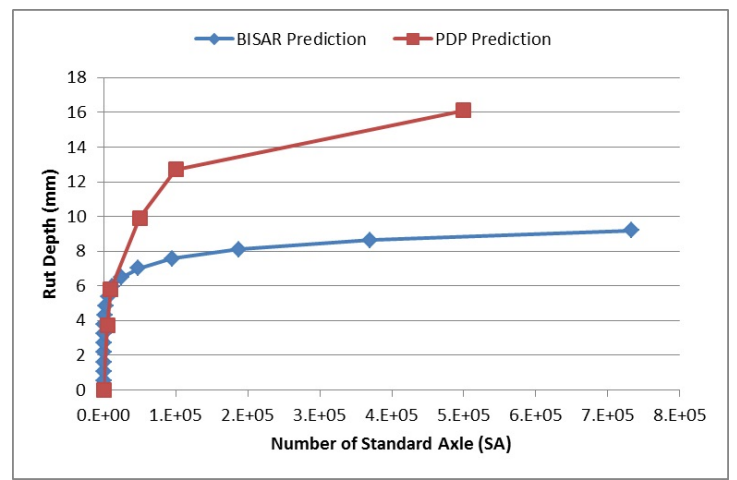

(a)

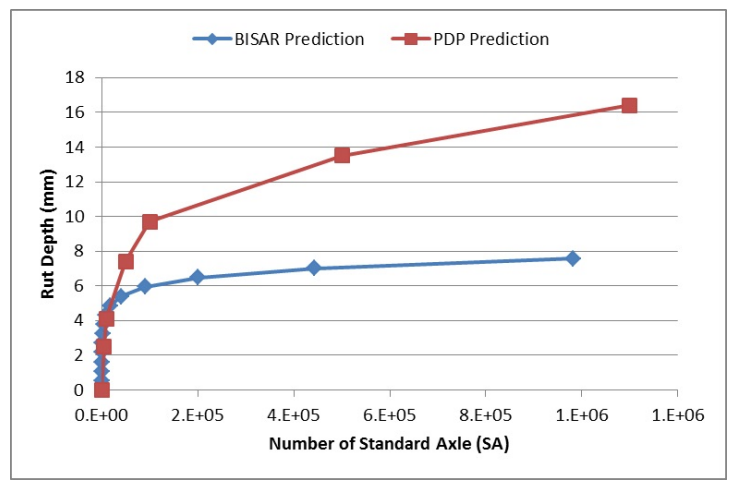

(b)

Figure 19: Field Prediction Results

it accurately and poor prediction was obtained.

\subsection{Limitations and Specific Data Required}

From the above discussion, it was noted that the data supplied was not enough to make a precise prediction. It is believed that to obtain an improved prediction compared to the field, the RLAT data should fulfil specific requirements. Firstly, the sample should be left in the RLAT until high deformation is reached; this will allow the sample to reach the tertiary stage, and consequently the peak will be detected, allowing Gaussian function fitting. Secondly, the temperature used in the RLAT should be the 'design' temperature in the field to avoid the assumption of linear viscous behaviour in determining the 
shift factor and to obtain more precise prediction. Ideally, the loading time in the RLAT should be consistent with the design speed for the road; however in most test equipment it is accepted that this may not be practical and so an adjustment may therefore be required. These suggestions for RLAT testing are recommended to be considered if the method in this paper is to be used to predict a field rut accurately.

\section{Conclusions}

The main type of permanent deformation in asphalt mixtures is rutting. Rutting appears in asphalt layers due to many reasons, such as very slow movement of a heavy vehicle, inadequate mixture properties and high temperature during loading. This paper has introduced an approach to predict rutting in asphalt mixtures, and several conclusions can be drawn:

- A linear viscous method was introduced aiming to predict the permanent deformation of the asphalt mixture. The method was based on using a multilayer linear computer program (BISAR) and inputting viscous parameters rather than elastic parameters. The information used to input to the program was the nonlinear properties of the mixtures derived from RLAT test data, specifically the viscosity of the asphalt mixtures as a function of strain.

- Six asphalt concrete slabs with different aggregate gradations were manufactured for this purpose and were tested in the wheel tracking test to generate the rut depth. After that samples were cored from outside the rut line and tested in the RLAT at the same loading stress, loading time, and testing temperature.

- Three temperatures were used 30,40 , and $50{ }^{\circ} \mathrm{C}$ to verify that the approach is applicable. The approach shows good ability to predict the wheel tracking rut depth at 30 and $40{ }^{\circ} \mathrm{C}$ for all the mixtures. At $50{ }^{\circ} \mathrm{C}$, only one dense sample was manufactured, and as expected the approach gave 
a poorer prediction than at other temperatures due to the uncertainty inherent in the tertiary stage of deformation.

- Field data were also analysed, and asphalt layers were simulated in BISAR. Cores were taken from outside the rut line in the field and tested in the RLAT but at a different temperature than the weighted average field temperature, a low stress level and a low number of cycles. The prediction of field rut depth was relatively poor and, the reason was mainly due to having insufficient RLAT data to determine the non-linear properties. It is recommended that if this approach is to be used to predict real rutting, then specific requirements for RLAT test conditions need to be met.

\section{Acknowledgement}

The authors of this paper would like to thank the University of Baghdad Ministry of Higher Education in Iraq for funding this research, and Aecom for providing field data for this research.

\section{References}

[1] S. Brown, C. Bell, The validity of design procedures for the permanent deformation of asphalt pavements, in: Volume I of proceedings of 4th International Conference on Structural Design of Asphalt Pavements, Ann Arbor, Michigan, August 22-26, 1977., no. Proceeding, 1977.

[2] R. Haas, A. Papagianakis, Understanding pavement rutting.

[3] C. Monismith, K. Inkabi, C. Freeme, D. McLean, A subsystem to predict rutting in asphalt concrete pavement structures, in: Volume I of proceedings of 4th International Conference on Structural Design of Asphalt Pavements, Ann Arbor, Michigan, August 22-26, 1977., no. Proceeding, 1977.

[4] S. Khanzada, Permanent deformation in bituminous mixtures, Ph.D. thesis, Civil Engineering, The University of Nottingham (2000). 
[5] G. Battiato, G. Ronca, C. Verga, Moving loads on a viscoelastic double layer: Prediction of recoverable and permanent deformations, in: Volume I of proceedings of 4th International Conference on Structural Design of Asphalt Pavements, Ann Arbor, Michigan, August 22-26, 1977., no. Proceeding, 1977.

[6] A. Collop, D. Cebon, M. Hardy, Viscoelastic approach to rutting in flexible pavements, Journal of Transportation Engineering 121 (1) (1995) 82-93.

[7] C. L. Monismith, K. E. Secor, Viscoelastic behavior of asphalt concrete pavements, in: International Conference on the Structural Design of Asphalt Pavements, Vol. 203, 1962.

[8] F. Moavenzadeh, R. Carnaghi, Viscoelastic response of sand asphalt beams on elastic foundations under repeated loading, Proceedings of the Association of the Asphalt Pour ing Technologists 35 (1966) 514-528.

[9] M. Nunn, Prediction of permanent deformation in bituminous pavement layers.

[10] C. A. Pagen, Dynamic structural properties of asphalt pavement mixtures, in: Intl Conf Structural Design Proc, Vol. 1, 1972.

[11] E. Thrower, Methods of predicting deformation in road pavements, in: Volume I of proceedings of 4th International Conference on Structural Design of Asphalt Pavements, Ann Arbor, Michigan, August 22-26, 1977., no. Proceeding, 1977.

[12] J. F. Hills, D. Brian, P. Loo, The correlation of rutting and creep tests on asphalt mixes, Tech. rep. (1974).

[13] S. Brown, Determination of young's modulus for bituminous materials in pavement design, Highway Research Record (431). 